\title{
EXCLUSIÓN SOCIAL Y EL CONTADOR
}

\section{SOCIAL EXCLUSIÓN AND ACCOUNTANT}

\author{
ZeLma Wong TorRes ${ }^{*}$ \\ Docente Asociada de la Facultad de Ciencias Contables, UNMSM

\section{Luisa Elena Salcedo Guzmán **} \\ Docente Asociada de la Facultad de Ciencias Contables, UNMSM
}

[Recepción: Abril de 2010 / Conformidad: Mayo de 2010]

\section{RESUMEN}

En este artículo, lo que se desea es mostrar la competencia del Contador Público y su responsabilidad social frente a la exclusión social, que debe transmitir la esencia de sus conocimientos basada en la historia que es el pasado frente al futuro que es la información virtual y que al hablar de pobreza debe sumergirse en estas dos comparaciones, no eludiendo su responsabilidad que le compete desde antaño y para ello debemos trasladarnos a la historia que refleja como hemos ido superando escollos hasta nuestros días.

Palabras clave: Exclusión social, pobreza, contabilidad, responsabilidad social.

\begin{abstract}
In this article what you want to show the jurisdiction of the CPA and its social responsibility face to the social exclusion, which should trasmit the essence of their knowledge based on the story that is the past face to the future the future which is the virtual information and to talk about poverty to be submerged in these two comparisons, not to shirk their responsibility as it shall from many year ago and we must move to the story that reflects how we have been overcoming hurdles today.
\end{abstract}

Key words: Social exclusion, poverty, accounting, social responsibility.

* Magíster en Ciencias Contables, UNMSM; Contadora Pública Colegiada Certificada. Docente Investigador de la Facultad de Ciencias Contables, UNMSM.

E- mail: zwongt@hotmail.com

** Contadora Pública Colegiada. Docente Investigadora de la Facultad de Ciencias Contables, UNMSM.

E-mail: luisalcedog@yahoo.es 


\section{INTRODUCCIÓN}

Cada vez se hace necesario que los Contadores Públicos se pongan la camiseta de la responsabilidad social que le compete manifestando su valor, su ética en lo que hace de importante para preservar la integración de todos los estados por lo que su mirada debe ir a la Historia o recordando el pasado y de allí ir escalando para llegar al presente, desechando lo que no estuvo correcto en el pasado y aprovechando y superando lo que estuvo bien, con el fin de lograr el éxito no solo empresarial, sino también de la clase trabajadora.

Quien no recuerda que la profesión contable pasó por diferentes etapas desde el quipu, la yupana hasta hoy día, que estamos en la época de la información virtual y que en su devenir profesional ha participado en diferentes empresas públicas y privadas por lo que la responsabilidad social del contador tiene mucho que ver con la exclusión social de hoy en día, por ser nuestra profesión que en su servicio muchas veces se hace más ricos a los ricos y más pobres a los pobres cuando se contabilizan el patrimonio de una empresa privada o pública

\section{Exclusión social y pobreza}

Citar la exclusión social es hablar de pobreza. Por lo que, en este artículo, haremos algunas breves definiciones.

Para todos, es perfectamente claro que pobres son aquellas personas o familias que no tienen la capacidad de satisfacer sus necesidades básicas.

Sin embargo, existen pobres que tienen activos, es decir son propietarios de varias formas de activos o capital, los trabajadores asalariados convertidos en trabajadores independientes o propietarios de recursos quienes podrían salir de la pobreza si se utiliza adecuadamente desde la estructura económica y la propiedad subyacente oculta del capital que posee.

Existen estudios sociológicos que tratan de explicar, por qué países en vías de desarrollo, crecen económicamente, sin embargo, el beneficio para los más pobres es poco o nada. Esto se explica por la desigual distribución del crecimiento dentro del país. Desigualdad que se perpetúa por el limitado acceso de la población a la tierra, al capital, a la educación, al servicio público y al empleo.

Muchos piensan que la población pobre no podrá crecer por falta de capital físico y capital humano, pero el tiempo está demostrando que el pobre se está organizando y logrando lo que los políticos no han podido, estos grupos $\mathrm{u}$ organizaciones están buscando financiamiento para poder explotar su tierra; sin embargo, es lamentable que el gobierno peruano, en base a triquiñuelas, esté vendiendo estos activos; o sea, la tierra de nuestros compatriotas pobres, bajo el argumento que no le ve mayor capacidad para desarrollarse. Grave error del gobierno, pues no tiene un estudio de las características de los grupos cohesionados cuyo objetivo es dar batalla para lograr lo que quiere o desea o sea su bienestar común.

Actualmente, el crecimiento está concentrado en pocos sectores de la economía con poco o nada efectos sobre los más pobres. La tierra es un capital propio, el acceso a los bienes de capital público y el capital humano pertenece a los más pobres por lo que el Estado debe contemplar estos tipos de capital para una futura producción más rentables.

La combinación adecuada debe ser: educación, salud, servicios públicos, acceso al crédito y reforma agraria, tratando que los grupos de pobreza sean competitivos más 
productivos aumentando sus ingresos, sean estos dependientes o independientes.

El crecimiento económico es el factor clave para reducir la pobreza debiendo efectuarse una distribución de los activos físicos y el capital humano. Clave para la reducción de la pobreza debe ser prestar mayor atención en la distribución de los activos e inversión agregada, así como, los mecanismos políticos y sociales para un mayor acceso de los pobres a los activos que son claves para el aumento de la productividad y los ingresos; todo esto depende de la oportunidad de participación que se dé a los pobres en el proceso de crecimiento.

La pobreza se da un desigual acceso de recursos y la lenta expansión de capacidades así como a la limitada capacidad del sistema institucional de convertir recursos y capacidades en derechos, resultado de que los pobres no tienen accesos a los recursos o cuando acceden es insuficiente y de baja calidad, siendo sus derechos muy limitados por no contar con recursos necesarios para utilizarlos.

La desigualdad es una restricción al crecimiento, la inadecuada distribución de activos afecta al crecimiento, no permite resurgir de la pobreza y la desigualdad. La desigualdad en el crecimiento se debe a las diferencias en el acceso de la población a activos productivos. La desigual distribución del capital humano y otros activos productivos representan las restricciones estructurales que limitan el crecimiento de América Latina y explica el pobre desempeño del Perú para reducir la pobreza.

\section{Los nuevos pobres o pobres recientes}

Al surgimiento del enfoque de exclusión social surge la noción de nuevos pobres o pobres recientes, sean estos pauperizados o empobrecidos para distinguirlos de los po- bres estructurales o permanentes en lo que la pobreza se ha perpetuado durante generaciones.

Los nuevos pobres son las familias que no lo eran hasta pocos años atrás, es la clase media que ha soportado fuertes crisis ante diversos embates en dos décadas pasadas; tienen atributos propios de la clase media: cultura, educación, en algunos casos viviendas heredadas, aspiraciones propias, pero sus ingresos y su inestabilidad laboral los colocan debajo del umbral de la pobreza, descenso del nivel de vida de todos los estratos sociales afectados, en especial a la clase media que no había transitado por el umbral de pobreza, debido a medidas políticas macroeconómicas.

Los nuevos pobres son obreros, empleados, informales, docentes profesionales y trabajadores jubilados, campesinos entre otros, conformando un verdadero movimiento de grupo. De acentuarse la situación, pasarían a ser pobres permanentes de una parte importante del sector están perdiendo su privacidad y comodidad debido a la baja de sus ingresos.

\section{El crecimiento del pro-pobre}

Está definido por el crecimiento que es bueno para los pobres, ganando, un poco más cambia la distribución de los ingresos relativos a través del crecimiento a favor de los pobres.

El crecimiento pro-pobre absoluto mide el crecimiento de ingresos de los pobres bajo la definición absoluta; basta que el ingreso de los pobres aumente en el tiempo para ser pro-pobre.

En cambio, el crecimiento pro-pobre relativo, implica reducción de la desigualdad; el ingreso de los pobres crece más rápido que el ingreso de los no pobres. 
Cuadro N.o 1. Evolución Porcentual de Pobreza. Perú 2004-2009.

\begin{tabular}{|c|c|c|c|c|}
\hline Año & $\begin{array}{c}\text { Población } \\
\text { (miles) }\end{array}$ & $\%$ Pobreza & $\begin{array}{c}\text { Pobres } \\
\text { (miles) }\end{array}$ & $\begin{array}{c}\text { Cambio } \\
\text { (miles) }\end{array}$ \\
\hline 2004 & 26,896 & $48.6 \%$ & 13,071 & \\
\hline 2005 & 27,219 & $48.7 \%$ & 13,256 & 185 \\
\hline 2006 & 27,546 & $44.5 \%$ & 12,257 & $(999)$ \\
\hline 2007 & 28,220 & $39.3 \%$ & 11,090 & $(1167)$ \\
\hline $2008^{*}$ & 28,807 & $36.2 \%$ & 10,428 & $(662)$ \\
\hline $2009^{*}$ & 29,132 & $34.8 \%$ & 10,138 & $(290)$ \\
\hline
\end{tabular}

$\left(^{*}\right)$ Poblacion Estimada según INEI Fuente: www.inei.gob.pe Elaboración propia

$\mathrm{Al}$ año 2009, en el Perú existían, aproximadamente, 10,138 000 personas afectadas por la pobreza, lo que constituye el $34.8 \%$ de la población total del país.

Una de las posibilidades de salir de la pobreza es por la educación y usos de los recursos familiares.

En todo esto, debe aplicarse la ecuación contable que tiene todo balance debiendo considerar los activos y los pasivos u obligaciones o deudas que tiene nuestro país, la economía de nuestro país se la está idealizando. ¿Quiénes? Los que están explotando nuestras riquezas en forma gratuita, de tal manera que no se nota el embalse que está sucediendo, que es a costa del pueblo y de los más pobres; sino, veamos el comportamiento de algunas empresas extranjeras con el pobre hermano peruano que no tiene quien lo defienda y si se le defiende en su derecho se le tilda de conflictivo con tal que el gobierno por este hecho haga lo que le dé la gana.

En el planeamiento estratégico, debe contemplarse las potencialidades y fortalezas que el país nuestro tiene y posee, y considerar las restricciones o debilidades que son muchas, sino preguntémosle a la corrupción que no deja que nuestro país salga de su subdesarrollo, teniendo tanta riqueza, tanto visible como escondida.

En contabilidad, el activo menos el pasivo nos da el capital; y el pasivo y capital están olvidados por el estado.

Es necesaria la responsabilidad de las empresas para cambiar el rostro de nuestro país, pero más necesaria es la solidaridad ciudadana.

\section{EXCLUSIÓN SOCIAL}

La exclusión social está relacionada directamente con el desempleo, la edad, la raza. Comprender la exclusión social de una nación conlleva a comprender el grado de pobreza por el que atraviesa, pues la exclusión social es uno de los enfoques, con el que se mide la pobreza.

Según el Banco Interamericano de Desarrollo (BID) Departamento de Desarrollo Sostenible: la exclusión social en los últimos años, se debe a una serie de prácticas sociales, económicas y culturales que resultan del acceso limitado a los beneficios del desarrollo a ciertas poblaciones en base a su raza, etnia, género y/o capacidades físicas, la misma afectaría principalmente a grupos indígenas o grupos de ascendencia africana, a mujeres, a personas con discapacidad y/o a las personas VIH positivas, dificultando su acceso a trabajos formales, a vivienda digna, servicios de salud adecuados, educación de calidad y al sistema de justicia.

Un estudio de Figueroa, Altamirano y Sulmont (1996) sobre exclusión social y desigualdad en el Perú, cuyo origen es el Proyecto Organización Internacional del Trabajo (OIT) y luego toma su curso propio. Para ellos, el mercado de trabajo genera exclusión económica debido a que no es capaz de absorber a toda la oferta de trabajo; en este 
sentido la desigualdad no es solo económica; al analizar la dimensión económica sistema productivo y mercados, hay que medir también la dimensión política la cual es poderosa en el ejercicio del poder, deberes, derechos, ciudadanía y cultura la desigualdad puede darse en una o más de estas dimensiones.

Figueroa distingue dos tipos de mercados los walrasianos y lo no walrasianos.

\section{Mercados Walrasianos}

Compran y venden las cantidades que deseen al precio vigente porque opera la competencia perfecta, resultado del equilibrio en el mercado de la cantidad ofrecida y la demanda, es decir, se rigen por los precios, sean competitivos o no, en un mercado perfectamente organizado desde el punto de vista de la competencia cuanto mayor sean los activos y mayor la cantidad de bienes y servicios que el individuo pueda adquirir en los mercados no walrasianos mayor será su ingreso real.

\section{Mercados no Walrasianos}

Se ajustan por cantidades o racionamiento cuantitativos, prevalece la competencia imperfecta e información imperfecta, no se compra o vende lo que se desea porque la incertidumbre y la información es imperfecta y los precios no son equilibrados, operan con exceso de oferta y/o demanda laboral, el crédito, el seguro, se ajustan al racionamiento.

Aquellos, pobremente dotados de activos sociales y culturales, serán más propensos a ser excluidos de los mercados no walrasianos, si el individuo es excluido del mercado laboral de crédito y de seguros, su ingreso será menor y más riesgoso, y su capacidad de acumulación de activos económicos disminuirá.

A quienes se le excluye del mercado laboral? A los trabajadores con los más bajos activos culturales, ubicándolos muchas veces al final de la línea en el proceso de racionamiento, mercados de créditos y seguros.

Lo que genera la desigualdad de ingresos en esta economía opera a través del mercado laboral implica una cierta distribución del ingreso entre las ganancias los salarios y los ingresos de los trabajadores independientes, también se explica la exclusión de un segmento de la fuerza laboral del empleo asalariado.

La pobreza es el resultado de un proceso social. La exclusión social de los mercados básicos será la causa de la pobreza; pero, la exclusión de otros mercados como los mercados, de bienes de consumo es un efecto.

Según el estudio de Figueroa (1996) asume el enfoque de exclusión social en su vertiente de la muldimensionalidad de la pobreza pues no reconoce que el problema no es un fenómeno exclusivamente económico sino que es un problema donde se superponen las dimensiones social, cultural y política.

El problema de los pobres no es solamente la escasez de recursos sino que son marginados por la sociedad y carecen de derechos reales o efectivos, debido a la desigualdad y exclusión son vistos como un proceso dinámico en el cual las desigualdades iniciales heredadas desde la colonia se multiplican y profundizan a través del tiempo.

La sobre oferta de la mano de obra seria la falta de acumulación de capital necesarios para absorber a toda la mano de obra el salario de equilibrio en el Perú es muy bajo.

El análisis que se haría es, porque trabajadores asalariados reciben sus ingresos y estos no le permiten salir de la pobreza, el salario mínimo legal del Perú se encuentra por deba- 
jo de la línea de pobreza, a esto hay que añadir a los pobres y excluidos que no perciben nada.

Se han ideados programas de compensación social distinguiéndose entre los nuevos o recientes pobres y los pobres antiguos o crónicos convirtiéndose la pobreza en un circulo vicioso por lo que es necesario estudiar la condición permanente de pobreza, desde un ángulo más amplio, sectorizando la población o de la pobreza estructural.

\section{RESPONSABILIDAD SOCIAL DEL CONTADOR}

El Contador además de generar información a la empresa, es un ser con conocimiento y capacidad de análisis que puede aportar ideas que ayuden al mejor funcionamiento de la comunidad en general, aquí ya estamos refiriéndonos a la responsabilidad social del contador.

La sociedad deposita su confianza en los contadores, ya que estos dan fe del buen manejo dentro de la empresa, teniendo presente que las empresas pagan impuestos, los que finalmente deben ser utilizados en la sociedad. El Contador dentro de una empresa cumple o debería cumplir una función interventora, ya que puede validar y aplicar procesos que la empresa pone en marcha, velar por que estos procesos refuercen la conservación del ambiente y a la vez el bienestar de la comunidad por medio de acuerdos sociales.

Jack Araujo menciona a este respecto que la contabilidad social esta "referido a hechos sociales tanto del recurso humano en la empresa como de las que suceden fuera de ellas en la comunidad en la que está inserta" ${ }^{1}$. Pues en estos tiempos, ya es una necesidad que el contador tome decisiones en relación a la gestión social.

Aquí convendría citar a Adela Cortina²: "reflexionar sobre lo ético de la sociedad civil equivale a conversar a iniciar una conversación, para tratar de construir un proyecto de sociedad que nos tenga en cuenta a todos, que no margine a nadie, que no posibilite la exclusión y que incluya la verdad a todos los miembros de la sociedad".

Si comparamos el principio rector de la contabilidad: Debe $=$ Haber con la frase citada por Adela Cortina, observamos que este enfoque no admite ningún tipo de exclusión, donde ese debe y la posesión son una expresión de inclusión verdadera a todos los miembros de la sociedad, sin marginación alguna.

En esta relación, el Contador asume no solo una responsabilidad ética, sino también social, pues Debe $=$ Haber expresa la igualdad del tú a tú, obliga al contador a dar una mirada más analítica a la sociedad, con miras a construir un futuro mejor con libertad y responsabilidad. La responsabilidad es un hecho que provoca obras productivas, Esta relación de igualdad que implica responsabilidad, es un hecho que provoca obras productivas.

De otra parte, la " $T$ ” esquemática contable, no solo debería representar un símbolo contable para el profesional en Contabilidad, sino, además, debe ver en ella la simbología del equilibrio.

La responsabilidad social del contable va más allá de obras sociales, la reflexión crítica la normatividad, su responsabilidad es una apuesta por el al desarrollo del conocimiento contable a través de las más sentidas necesidades de la sociedad en general. De allí

1 Araujo, Jack Alberto. Contabilidad social. Tiempos Gráficos Ediciones, p. 35, Medellín, Colombia, 1999.

2 Cortina, Adela. Democracia participativa y sociedad civil. Una ética empresarial. Siglo del hombre editores, pp. 70-72. Bogotá, 1998. 
que la relación de equilibrio Debe=Haber, propicia acuerdos en la diferencia, logrando la armonía.

El Contador debe brindar apoyo en el sentido del pueblo, conciliar diferencias empresa-comunidad, tolerancia y respeto hacia otras culturas, actuar bajo la lógica de una estructura adecuada según las necesidades de su entorno, e incorporando conocimiento común, ya que el Contador debe actuar socialmente propiciando el equilibrio, la justicia y la igualdad.

Tengamos presente que la contabilidad presenta una contribución al sistema económico, éste juega un papel fundamental si de consolidar la brecha entre pobres y ricos se trata. El Contador debe despertar una reflexión crítica, dejar de lado la lógica del desarrollo del capitalismo que solo busca mantener o generar más pobreza y miseria y por ende exclusión.

El Contador de hoy tiene por reto el forjarse una actitud crítica y reflexiva ante las prácticas económicas, contables y administrativas, tengamos presente que el Contador es el fedatario de las buenas prácticas dentro de una empresa. Requiere una participación activa en la transformación y construcción de la realidad económica-social, en busca del bienestar, igualdad y equilibrio social. Su postura dentro de sus análisis debe apuntalar a la construcción de respuestas a las necesidades sociales.

El Contador y el Sistema Nacional de contabilidad tienen la función social de contribuir y propiciar la formación de un Estado donde la contribución al bien común sea adecuada y significativa. El apoyo del Contador al respecto es imprescindible en la rendición de cuentas, ya que este es el pilar básico de la transparencia. La información permite tomar conciencia de lo hecho y lo por hacer, principio de la responsabilidad social.

\section{CONCLUSIONES}

- Vemos como fundamental la participación del Contador Público más humanizado con la realidad y la necesidad de adaptarse a los cambios, no limitarse a los cálculos de números fríos, los cuales deben reflejar la realidad y su proyección a futuro.

- La realidad afecta a la gran mayoría de las culturas y organizaciones; cada vez el cliente es más exigente, pero esa exigencia debe ir de la mano del cuidado de los sueldos y/o salarios que se fijan dentro de su empresa y su aporte social que toda empresa debe hacer frente a los problemas humanos de sus trabajadores por ser los que toman decisiones, y quienes con su esfuerzo y entrega coadyuvan al éxito y desarrollo de la empresa.

- Que el Contador Público retome su liderazgo que lo ha dejado por comodidad del facilismo olvidándose de su entorno, dejando a la merced de informes fríos los resultados de la empresa olvidándose que es corresponsable de la pobreza y exclusión social, que debe erradicarse y lograr que surja el desarrollo no solo empresarial, sino también el de los trabajadores que con su esfuerzo y entrega logran que la empresa resulte exitosa, trabajadores que con sus buenos ingresos lograrán que sus familias salgan adelante en estudio, salud, bienestar que redundará en el éxito del país.

\section{REFERENCIAS BIBLIOGRÁFICAS}

1. Araujo Ensuncho, Jack Alberto (1999). Contabilidad social. Segunda edición. “tiempos Gráficos”. Medellín.

2. Bahamón, Berenice (1992). Sociología de las profesiones. Ediciones CIS. Madrid. 
3. Cortina, Adela (1985). "Razón comunicativa y responsabilidad solidaria: ética y política”. En: K.O. Apel. Salamanca: Sígueme, Colección: Hermeneia; 25.

4. Cortina, Adela (1998). Democracia participativa y sociedad civil. Una ética empresarial. Siglo del hombre editores. Bogotá.

5. Fernández, José Luis; Hortal, Augusto (1994). Ética de las profesiones (Compendio) Madrid, Ediciones Universidad Comillas.

6. Franco, Rafael (1997). Reflexiones contables. Teoría, educación y moral. 2. ${ }^{\mathrm{a}}$ ed., Editorial investigar Editores, Armenia, Colombia.

7. Garzón, Francisco (1987). Biblioteca de Babel. SIRUELA Ediciones (dentro de la colección de lecturas fantásticas), Madrid.

8. Moneva, J. M. y Llena, F. (1996). “Análisis de la información sobre responsabilidad social en las empresas industriales que cotizan en bolsa”. En Revista Española de Financiación y Contabilidad. N. ${ }^{\circ}$ 87, Zaragoza.

9. Sínisterra, Gonzalo (1989). Contabilidad la base para las decisiones comerciales (Vol. I), adaptación de "contabilidad base para la toma de decisiones". Vol. I., 2. a ed. Editorial McGraw-Hill, Colombia.

10. Weber, Marx (1964). Economía y sociedad. México F. C. E. 